\title{
Intensive care management of patients with acute liver failure with emphasis on systemic hemodynamic instability and cerebral edema: A critical appraisal of pathophysiology
}

\author{
Fin Stolze Larsen $\mathrm{MD} \mathrm{PhD}^{1}$, Bent Adel Hansen $\mathrm{MD}^{1}$, Andres T Blei MD ${ }^{2}$
}

FS Larsen, BA Hansen, AT Blei. Intensive care management of patients with acute liver failure with emphasis on systemic hemodynamic instability and cerebral edema: A critical appraisal of pathophysiology. Can J Gastroenterol 2000;14(Suppl D): 105D-111D. Acute liver failure (ALF) is a devastating disease leading to multiorgan dysfunction. The most dramatic impact of ALF is on the brain, as hepatic encephalopathy and intracranial hypertension (IH) develop. IH is associated with systemic hemodynamic instability, alterations in the regulation of cerebral blood flow and the development of cerebral edema. This review focuses on the pathophysiology of $\mathrm{IH}$ with special emphasis on cerebral blood flow and the development of cerebral edema. Based on these considerations, both traditional and new treatments for the management of $\mathrm{IH}$ in the future are discussed.

Key Words: Ammonia; Brain; Cerebral blood flow; Cerebral edema; Fulminant hepatic failure; Intracranial pressure
Traitement intensif de l'insuffisance

hépatique aiguë mettant l'accent sur

l'instabilité hémodynamique systémique et

l'œdème cérébral : Évaluation critique de la physiopathologie

RÉSUMÉ : L'insuffisance hépatique aiguë (IHA) est une maladie dévastatrice qui entrâne une dysfonction pluri-organique. L'impact le plus dramatique de l'IHA se produit sur le cerveau, puisque l'encéphalopathie d'origine hépatique et l'hypertension intracrânienne (HI) se développent. L'HI est associée à une instabilité hémodynamique systémique, à des altérations de la régulation du débit sanguin cérébral et au développement d'un œdème cérébral. Cette synthèse met l'accent sur la physiopathologie de l'HI en insistant davantage sur le débit sanguin cérébral et le développement de l'œdème cérébral. Sur la base de ces considérations, on aborde les modalités thérapeutiques classiques et novatrices pour le traitement de l'HI à l'avenir.

\begin{abstract}
A cute loss of liver function is a devastating disease with a high mortality rate. It results in rapidly progressing multiorgan dysfunction, with circulatory instability, renal failure and sepsis as conspicuous clinical features. However,
\end{abstract}

the most dramatic impact is on the brain. Hepatic encephalopathy (HE) in acute liver failure (ALF) is often associated with the development of intracranial hypertension (IH). A rise in intracranial pressure (ICP) is a unique and distinctive

This mini-review was prepared from a presentation made at the 1998 World Congress of Gastroenterology, Vienna, Austria, September 6 to 11, 1998

${ }^{1}$ Department of Hepatology, Rigshospitalet, Copenhagen University Hospital, Denmark; ${ }^{2}$ Department of Medicine, Veterans Administration

Lakeside Medical Center, Northwestern University, Chicago, Illinois, USA

Correspondence and reprints: Dr FS Larsen, Department of Hepatology A-2121, Rigshospitalet, University of Copenhagen, Blegdamsvej 9 ,

DK - 2100 Copenhagen $\varnothing$, Denmark. Telephone +45-35452357, fax +45-35452913, e-mail stolze@post3.tele.dk

Received for publication March 14, 1999. Accepted March 18, 1999 
feature of ALF, which is not seen in multiorgan failure caused by other critical illnesses.

The pathophysiology of circulatory instability is not fully understood but seems closely related to a decrease in systemic vascular resistance. The neurochemical mechanism responsible for $\mathrm{HE}$ is still controversial, but IH in ALF is closely related to the development of cerebral edema (1) and alterations in cerebral blood flow (CBF) (2).

This review first briefly defines ALF and describes the most important etiological causes. Then the focus turns to the pathophysiological changes in the systemic and cerebral circulation, with a special emphasis on the development of cerebral edema in ALF. Based on these considerations, hemodynamic treatment modalities are discussed.

\section{DEFINITION}

The fulminant form of liver failure was originally defined as a syndrome with the onset of HE occurring within eight weeks after the first clinical symptom of liver disease, eg, jaundice, malaise, nausea or right abdominal discomfort (3). This ambiguous definition distinguishes patients with acute liver injury from patients with $\mathrm{HE}$ as a complication of chronic liver disease. However, a subgroup of patients with liver failure and $\mathrm{HE}$ have a longer interval from the first sign of liver dysfunction to the development of $\mathrm{HE}$ without having chronic liver failure. This subgroup of patients have been termed to suffer from subacute liver failure (4) or late onset fulminant hepatic failure (5). Separating patients with ALF injury into subgroups of patients with hyperacute, acute and subacute liver failure has been proposed (6) to delineate a more appropriate management strategy, including liver-assist methods and liver transplantation (7). Thus, the current definition of ALF is dependent on the development of $\mathrm{HE}$, even though it is associated with little prognostic and pathophysiological information. In fact, the extent of liver injury, as measured by liver function tests, is the single most important determinant of the outcome for patients with ALF (8).

\section{INCIDENCE AND ETIOLOGY}

It is estimated that there are about 2000 cases of ALF in the United States each year. Similarly, the incidence of ALF is approximately eight/1,000,000 in Denmark. Acetaminophen intoxication accounts for approximately $50 \%$ of the ALF patients in the United Kingdom (9) and Denmark (10). Acetaminophen overdose has also become the most common cause of ALF in American liver transplantation centres, and accounts for approximately $20 \%$ of ALF patients (11). Acute viral hepatitis (type A and B) is the predominant cause of ALF in central and southern Europe. Acute viral hepatitis E has been reported to be a frequent cause of subacute liver failure in pregnant women in India. Other causes of ALF may be mushroom intoxication, drug-induced hepatotoxicity (ecstasy halothan, valproate and disulfiram), autoimmune hepatitis, cardiac failure and inherited metabolic diseases (reviewed in 12).

\section{PATHOPHYSIOLOGY \\ Systemic circulation}

Liver failure induces cardiovascular dysfunction. Clinical examination reveals warm peripheries and bounding pulses. Using a dye-dilution technique in patients with chronic liver disease, Kowalski and Abelman (13) found that cardiac output and heart rate were increased while arterial pressure was reduced, ie, a hyperdynamic systemic circulation. Studies of patients with ALF have shown similar cardiovascular alterations (14-16). Trewby and Williams (14) reported that 82 of 94 patients with ALF had a systolic arterial pressure of less than $80 \mathrm{mmHg}$ for more than $1 \mathrm{~h}$, and low systemic vascular resistance and cardiac filling pressures have also been demonstrated (17). With volume replacement, systolic arterial pressure above $80 \mathrm{mmHg}$ can be maintained in most patients with ALF, supporting the concept that 'peripheral' arteriolar dilation contributes to the development of arterial hypotension.

It is unlikely that low systemic vascular resistance is centrally induced, even though cerebral edema often develops in patients who exhibit a hyperdynamic state. This is because the systemic circulatory abnormalities are also present in patients with cirrhosis who rarely develop cerebral edema and $\mathrm{IH}$.

Both patients with cirrhosis and patients with ALF develop portal hypertension. Leakage of endotoxins from the gut to the portal blood (translocation) and/or the lymph nodes may result in elevated systemic endotoxin levels because portal blood bypasses the liver via collaterals. In patients with ALF, it is also assumed that endotoxins are shunted through the failing liver without being cleared by Kuppfer cells. Endotoxins induce the release of various cytokines (tumour necrosis factor-alpha [TNF- $\alpha$ ], interleukin [IL]-1 and IL-6), which are potent stimulators of the inducible isoform of nitric oxide synthetase. The plasma concentration of TNF- $\alpha$, IL- $1 \beta$ and IL- 6 in the inflammatory host defense system are increased in patients with $\operatorname{ALF}(18,19)$. There is accumulating evidence that hyperdynamic circulation in both chronic liver failure and ALF, with high cardiac output and low systemic vascular resistance, may result from cytokine activation of the endothelium, which releases excessive amounts of endothelium-derived nitric oxide (2022).

Patients with an increased, mixed venous lactate have a poor prognosis if it develops after adequate volume replacement (23). Mixed venous lactate concentration is inversely correlated to systemic vascular resistance (17). Arterial hypotension and low systemic vascular resistance may result from the development of arteriovenous shunts. Arteriovenous shunts and perfusion of non-nutritive capillaries have been considered main reasons for the development of tissue hypoxia, lactic acidosis and multiorgan failure (Table 1) $(16,22,24)$. It has been suggested that systemic lactic acidosis results from insufficient blood flow, especially in the splanchnicus and brain (22). This concept of tissue hypoxia is supported by the observation that oxygen consumption increases during infusion of prostacyclin and $N$-acetylcystein, ie, as oxygen extraction increases. However, recent studies of sys- 
TABLE 1

Common complications in fulminant hepatic failure

Hepatic encephalopathy
Hypoglycemia
Cerebral edema
Arterial hypotension
Respiratory insufficiency
Tissue hypoxia
Lactic acidosis
Renal failure
Electrolyte disorders
Infections/sepsis

temic and regional circulation have failed to support this concept of 'pathological supply dependency'. This may result from methodological problems, because the same techniques (ie, pulmonary artery catheter and Fick's principle) were used to calculate both systemic oxygen delivery and consumption in the first studies $(16,22,24)$. Walsh and co-workers (25) recently used two independent techniques to determine systemic oxygen delivery and consumption during $\mathrm{N}$-acetylcystein infusion into patients with ALF, and failed to demonstrate profound changes in systemic oxygen consumption. Also, Clemmesen et al (26) demonstrated that in patients with ALF, splanchnic blood flow is increased without demonstrating tissue hypoxia. On a similar note, the cerebral metabolic rate for oxygen remains constant despite the rise in CBF by noradrenaline (27). These results indicate that both the splanchnic organs and the brain are receiving sufficient perfusion for the maintenance of oxidative metabolism. Thus, it has not yet been proven that a critical reduction in oxygen extraction and consumption are of any pathophysiological importance in the development of multiorgan failure in ALF.

\section{$\mathrm{CBF}$ and cerebral edema}

One of the most common causes of death in ALF is IH, which develops in approximately $60 \%$ to $80 \%$ of patients (28). Its pathophysiology is not settled, but fruitful progress has recently been made in understanding some of the mechanisms involved.

In contrast to other organs, the combined brain volume, consisting of tissue, blood and extracellular fluid, submits to the physical limitations of the skull. The total volume must remain unchanged to avoid a rise in ICP (Figure 1). A primary rise in brain volume caused by cytotoxic edema leads to a decompensated state, where a small increase in cerebral blood volume results in a serious rise in ICP. Thus, the gradual development of both cerebral hyperemia and cerebral edema will rapidly influence ICP.

Cerebral edema: Three explanations have to be considered for a pathophysiological explanation of cerebral edema in ALF. First, accumulation of osmolytes within astrocytes may be of importance (the glutamine hypothesis) (29). Second, $\mathrm{CBF}$ regulation may be altered (the hyperemia hypothesis)

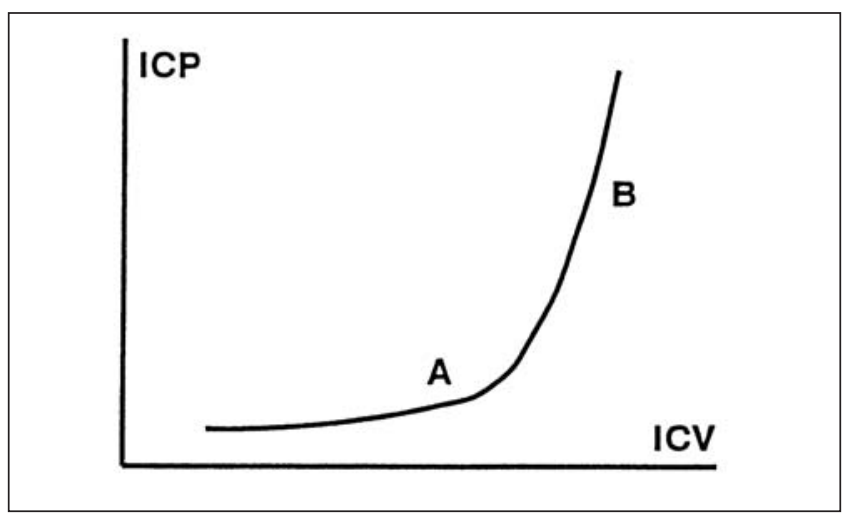

Figure 1) The relation between intracranial volume (ICV) and intracranial pressure (ICP) is initially compensated (A) but later incompensated (B)

(2). Third, accumulation of compounds released from the necrotic liver may enter the brain and cause swelling.

Glutamine hypothesis: For decades, ammonia intoxication has been considered pathophysiologically important for the development of HE. Only recently has a study demonstrated that arterial ammonia concentration is related to cerebral edema and cerebral herniation in patients with ALF (30). This effect of ammonia is not fully understood, but could result from characteristics of ammonia metabolism in the brain, an organ that lacks a complete urea cycle. Cerebral detoxification of ammonia occurs by either the amination of alpha-ketoglutarate to glutamate or the ATP-dependent amidation of glutamate to glutamine by the enzyme glutamine synthase. Thus, glutamine concentration increases within astrocytes during ammonia intoxication both in vitro (31) and in vivo (32). Because glutamine is a quantitatively important osmolyte, water diffuses into the astrocytes and results in cell swelling, ie, cytotoxic edema. In chronic liver failure (ie, portacaval anastomosis in the rat), a compensatory decrease of other osmolytes, such as myo-inositol and taurine, restores normal osmolyte and water content in the astrocytes. This is in contrast to rats with ALF, in which the total osmolyte and water content increases (33). A reduction in cerebral blood volume, ie, CBF, in the setting of cerebral edema, may be the only way to avoid IH (Figure 1). The regulation of $\mathrm{CBF}$ is of vital importance to understanding $\mathrm{IH}$ in the setting of cerebral edema.

Cerebral hyperemia: Normally, CBF is closely regulated by brain metabolism (34). The coupling of CBF and metabolic requirements implies that reduced cerebral activity, eg, after sedation, is followed by a decrease in CBF. Seizures, on the other hand, increase CBF as metabolism is raised (35). Because the cerebral oxygen metabolism is inevitably reduced by approximately $50 \%$ in ALF, CBF would also be expected to decrease to a similar degree, ie, to approximately 20 to $25 \mathrm{~mL} 100 \mathrm{~g} \mathrm{~min}^{-1}$. However, a wide intra- and interindividual CBF variation has been reported in ALF, ie, from

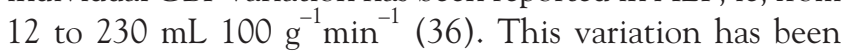
shown to result, at least to some extent, from alterations in arterial pressure (37).

Normally, arterial pressure has no influence on CBF, 


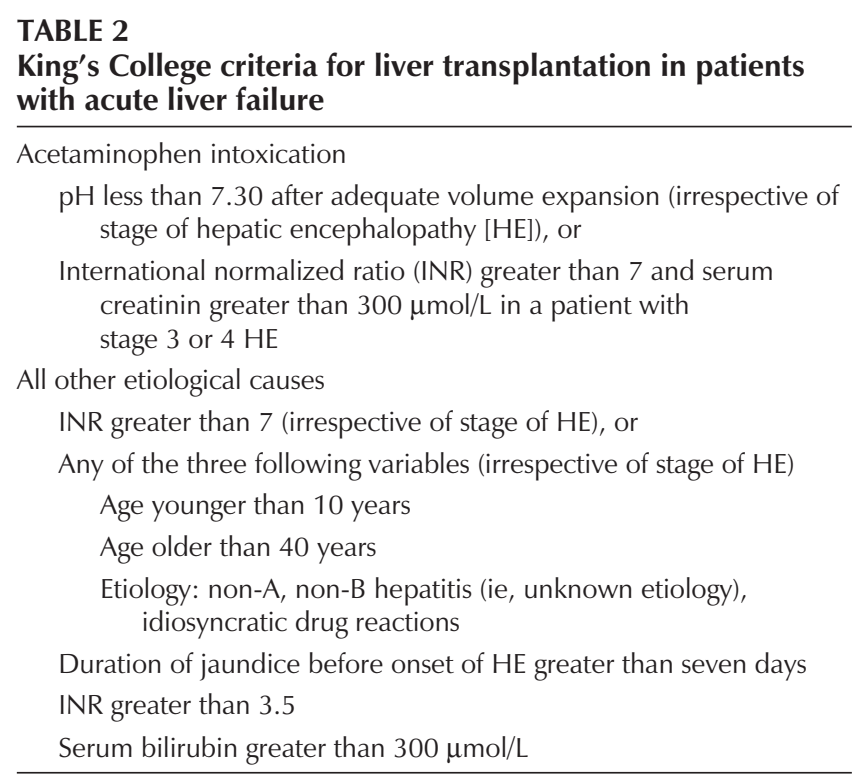

Data from reference 23

ie, CBF remains constant. This is due to reactive dilation or constriction of cerebral resistance vessels within a wide range of arterial blood pressures; thus, $\mathrm{CBF}$ is autoregulated (38). In ALF, CBF autoregulation is absent $(27,37,39)$. As a result, circulatory instability with episodes of arterial hypotension may result in brain hypoxia and lactate efflux. For example, 21 of 30 patients with severe ALF had evidence of nonoxidative cerebral metabolism at a late stage of the disease (40). In the initial stage of ALF, cerebral hypoxia seems less frequent, and it is not obvious that cerebral hypoxia is pathophysiologically involved in cerebral edema (27). Conversely, arterial hypertension may result in an increase in CBF to an extent that exceeds the actual metabolic demands of the brain, ie, cerebral 'luxury perfusion' $(2,36)$. This may lead to a critical increase in cerebral blood volume and ICP. Also, the hydrostatic capillary pressure may exceed the colloid osmotic pressure and have a profound influence on water movement into the brain (vasogenic edema). Agitation, seizures, IH (41) and even hemorrhage can develop in ALF, and may result from luxury perfusion. Thus, pain, fever, insufficient sedation, renal failure with hypervolemia, and prolonged use of dopamine or noradrenaline initiated for 'extra-cerebral' reasons may induce cerebral hyperemia and edema, and should be avoided.

Why is autoregulation lost? Cerebral arteriolar dilation could explain the development of luxury perfusion CBF $(37,39)$. The vasodilatory response to hypercapnia becomes blunted because the arterioles are already maximally dilated (2,42). Indeed, CBF autoregulation can be restored by the induction of acute hypocapnia through mechanical hyperventilation, a manoeuvre that results in arteriolar vasoconstriction (43).

Toxins from the failing liver: There is some evidence that patients with ALF waiting for emergency liver transplantation may benefit from total hepatectomy as the systemic hemodynamics stabilize $(7,44)$. Also, cerebral edema and $\mathrm{IH}$
TABLE 3

Methods for evaluation of the prognosis in acute liver failure

\begin{tabular}{lc}
\hline Method & Reference \\
\hline King's College criteria & 23 \\
Factor V - Clichy criteria & 66,67 \\
Galactose elimination capacity & 8,68 \\
Arterial ketone body ratio & 69 \\
Japanese severity index & 70 \\
Computed tomography scan of liver volume & 71 \\
Transjugular liver biopsy & 72 \\
Plasma GC-globulin & 73 \\
\hline
\end{tabular}

seem to be reduced by hepatectomy (45). Moreover, Ejlersen et al (46) reported that a hepatectomy ameliorated cerebral hyperemia and partially restored regulation of CBF in a patient with ALF. It is not clear why these hemodynamic features improve after hepatectomy, but hypothermia may be a part of the explanation (47). Hypothermia normally increases systemic vascular resistance (SVR) and decreases CBF in the experimental model of ALF (47). The idea for performing hepatectomy in patients with ALF, even if a donor liver is not available to secure subsequent liver transplantation, is that toxic substances released from the failing liver are assumed to be responsible for the development of hemodynamic instability and cerebral edema. Such substances may be intracellular components or membrane fragments (29). However, it may be worth noting that other conditions with massive cell lysis, such as necrotizing pancreatitis, rhabdomyolysis, hemolysis and burns, do not result in brain edema and IH (29). Patients with ALF differ from patients suffering from these other critical conditions because they have severely elevated arterial ammonia concentrations resulting from the failing liver releasing large amounts of ammonia (30). It is not clear whether removal of the necrotic liver decreases the efflux of ammonia from the splanchnic circulation; further study is needed.

\section{CRITICAL CARE MANAGEMENT}

It is important to emphasize that the following proposal for the monitoring and management of systemic and cerebral hemodynamics should not delay efforts seeking to establish prognosis and regain liver capacity either by symptomatic support (and artificial liver-assist methods) or by liver transplantation.

\section{Prognosis and basic handling}

Because approximately half of the patients with severe ALF survive without transplantation, it is important to determine the prognosis. In most centres, the King's College criteria (Table 2) (23) or the Clichy criteria for transplantation are used (48). But also, liver function tests such as galactose elimination capacity may be of value in selecting patients for emergency liver transplantation (Table 3) (8). However, a detailed discussion on the prognostic markers of ALF is beyond the scope of this work; for extensive reviews on this is- 
TABLE 4

Previously proposed critical limits of systemic hemodynamic parameters in acute liver failure

Mean arterial pressure greater than $60 \mathrm{mmHg}$

Pulmonary capillary wedge pressure 10 to $18 \mathrm{mmHg}$

Oxygen delivery greater than $700 \mathrm{~mL} / \mathrm{min} / \mathrm{m}^{2}$

Oxygen consumption greater than $175 \mathrm{~mL} / \mathrm{min} / \mathrm{m}^{2}$

Oxygen extraction greater than $12 \%$

Data from reference 22

sue, see references 9 and 12 .

Transferring the patient to an experienced intensive care unit at a liver transplantation centre familiar with handling patients with ALF should be considered, even if the patient has medical or psychosocial contraindications to liver transplantation. Before transportation it is important to correct for hypoglycemia by an intravenous infusion of $20 \%$ glucose, and for metabolic acidosis and arterial hypotension by aggressive volume expansion with colloids, crystalloids, fresh frozen plasma or erythrocytes. Also, patients with stage 3 to $4 \mathrm{HE}$ should have the trachea intubated and be switched to mechanical ventilation with a partial pressure of carbon dioxide in arterial gas of approximately 30 to $35 \mathrm{mmHg}$ (approximately 4.0 to $4.5 \mathrm{kPa}$ ). If sedation is indicated for allowing controlled ventilation, short acting benzodiazepines and morphine are preferred. If these basic precautions cannot be fulfilled, the patient should be stabilized in the local intensive care unit before transportation.

\section{Monitoring and treatment of systemic hemodynamic instability}

Appropriate management, regardless of the decision to proceed with liver transplantation, should include the placement of arterial and central venous catheters. In patients with systemic hemodynamic instability who do not respond to volume expansion or achieve adequate cardiac filling pressures, the insertion of a pulmonary artery catheter is needed (Table 4). Central hemodynamics should be measured two or three times a day, following any change in inotropic support, or during any acute deterioration in arterial pressure.

Noradrenaline is the agent of choice if volume expansion is insufficient, and should be increased until the effect on arterial pressure is accomplished.

Low-dose dopamine, used to preserve or restore renal function, has not been demonstrated to be of any value for patients with ALF. Occasionally, patients may develop low cardiac output syndrome, which is associated with a poor prognosis. In these patients, low dose dopamine, dobutamine and adrenaline may be of value to increase cardiac output and arterial pressure. Transthoracic echocardiography should be performed to exclude pericardia effusion and/or hypokinesis. In addition, plasma magnesium and calcium ions, and phosphate levels should be determined and corrected.

Sudden deterioration in arterial pressure and/or SVR often results from the development of sepsis. In fact, sepsis
TABLE 5

Proposed critical limits of cerebral hemodynamics in acute liver failure with relevant references in brackets

Intracranial pressure greater than $30 \mathrm{mmHg}$ (67)

Cerebral perfusion pressure less than $40 \mathrm{mmHg}$ for more than $2 \mathrm{~h}(41,58)$

Internal jugular oxygen saturation greater than $50 \%$ and less than $75 \%$ (63)

Cerebral blood flow velocity in the middle cerebral artery as determined

by transcranial Doppler sonography greater than $100 \mathrm{~cm} / \mathrm{s}$ (61)

should always be suspected in patients with ALF, because it is also a major cause of death (22).

According to the 'intoxication concept' that cytokines may be important for the development of low SVR, one strategy to maintain vascular tone would be to decrease the plasma levels of endotoxins and cytokines. In fact, clearance procedures such as high volume plasmapheresis re-establish normal systemic arteriolar tone $(26,49)$. Various hemodialysis procedures do not increase SVR, probably because the filter pore size does not allow TNF to be removed by the system (50). It remains to be established whether biological 'liver assist devices' influence cytokine status and systemic hemodynamics.

\section{Monitoring cerebral hemodynamics}

ICP: To preserve normal intracranial compliance, treatment has traditionally been based on the monitoring of ICP for the calculation of cerebral perfusion pressure (CPP) (mean arterial pressure minus ICP) of patients with ALF (51). Thus, the reliablity of ICP monitoring becomes critically important for medical decisions with regard to the use of mannitol, sedation, hypothermia and liver transplantation. The accuracy of ICP monitoring depends on the method chosen, eg, epidural, subdural, parenchymous or intraventricular ICP catheters; epidural monitoring is the most safe but also the most unreliable method (52). Drift of the transducer, bend of catheters, wrong calibration or displacement during nursing or interventions may influence and change these parameters. Thus, aggressive and potentially dangerous treatments may be instituted on a false basis. ICP and CPP should always be interpreted critically, always in combination with a close evaluation of clinical condition before the escalation of medical treatment is instituted, and especially before liver transplantation is considered to be contraindicated (53). In a retrospective study, CPP has been demonstrated to have low predictive values in regard to brain death (54). Patients with $\mathrm{CPP}$ as low as $15 \mathrm{mmHg}$ have survived without transplantation or neurological deficits (55), despite that the claimed critical limit of CPP is $40 \mathrm{mmHg}(41)$. So, ICP monitoring and CPP calculation may be less important to the outcome in ALF patients than previously assumed.

Internal jugular vein oxygen saturation monitoring: Recently, it has been advocated that cerebral monitoring should focus on CPP in addition to ICP (Table 5). Relative changes in $\mathrm{CBF}$ can be monitored by internal jugular vein oxygen saturation $\left(\mathrm{SvjO}_{2}\right) ; \mathrm{SvjO}_{2}$ also gives direct information on brain oxygenation status (56). 
$\mathrm{SvjO}_{2}$ below approximately $55 \%$ is associated with cerebral symptoms both in those who are healthy and in patients with liver failure (57). A prolonged (period of minutes) decrease in $\mathrm{SvjO}_{2}$ to below 55\% may result in cerebral hypoxia and edema. Accordingly, mean arterial pressure should be increased instantaneously by volume expansion and/or noradrenaline. In some patients, $\mathrm{CBF}$ increases during the course of ALF, possibly due to gradual cerebral arteriolar vasodilation, and $\mathrm{SvjO}_{2}$ may increase to above $75 \%$ (58). The prognosis for patients with uncorrected high $\mathrm{SvjO}_{2}$ and cerebral edema is very poor $(54,58)$. In such cases, $\mathrm{SvjO}_{2}$ should be decreased by mechanical hyperventilation until $\mathrm{SvjO}_{2}$ is maintained within the normal range, because acute hyperventilation induces precapillary hypocapnic arteriolar constriction (59).

\section{Treatment of IH}

Mannitol infusion is the main treatment for IH. Not only is ICP reduced, but $\mathrm{CBF}$ and the cerebral metabolic rates of oxygen and lactate increase $(40,60)$. This effect is probably the result of an increase in colloid osmotic pressure in the cerebral capillaries and a reduction in interstitial water content.

Acute hyperventilation decreases $\mathrm{CBF}, \mathrm{SvjO}_{2}$ and ICP (61). Although hyperventilation has been considered inappropriate in intensive care units, hyperventilation is an indispensable and powerful part of the available treatment modalities for IH. Short term hyperventilation should be instituted to terminate $\mathrm{IH}$ episodes as long as the $\mathrm{SvjO}_{2}$ level can be maintained above 55\% (43).

Barbiturates are still used for the treatment of IH to reduce intracranial blood volume by precapillary hypometabolic arteriolar constriction. In a prospective study of ALF and IH, a significant reduction in ICP was demonstrated after the administration of thiopental, although the effect was only temporary (62). Although arterial pressure is decreased, $\mathrm{CPP}$ remains unchanged, and it has not been determined if

\section{REFERENCES}

1. Blei AT. Cerebral edema and intracranial hypertension in acute liver failure: distinct aspects of the same problem. Hepatology 1991; 13:376-9.

2. Larsen FS, Adel Hansen B, Pott F, et al. Dissociated cerebral vasoparalysis in acute liver failure. A hypothesis of gradual cerebral hyperaemia. J Hepatol 1996;25:145-51.

3. Trey C, Davidson LS. The management of fulminant hepatic failure. In: Popper H, Schaffner F, eds. Progress in Liver Disease. New York: Grune $\&$ Stratton, 1970;282-98.

4. Bernuau J, Rueff B, Benhamou J. Fulminant and subfulminant liver failure: definitions and causes. Semin Liver Dis 1986;6:97-106.

5. Gimson AE, O'Grady J, Ede RJ, Portmann B, Williams R. Late onset hepatic failure: clinical, serological and histological features. Hepatology 1986;6:288-94.

6. O'Grady JG, Schalm SW, Williams R. Acute liver failure: redefining the syndromes. Lancet 1993;342:273-5.

7. Bismuth H, Samuel D, Castaing D, Williams R, Pereira SP. Liver transplantation in Europe for patients with acute liver failure. Semin Liver Dis 1996;16:415-25.

8. Tygstrup N, Ranek L. Assessment of prognostic factors in fulminant hepatic failure. Semin Liver Dis 1986;6:129-37.

9. Riordan SM, Williams R. Cause and prognosis in acute liver failure. Liver Transpl Surg 1999;5:86-9.

10. Larsen FS, Kirkegaard P, Rasmussen A, Hansen BA. The Danish liver transplantation program and patients with serious acetaminophen intoxication. Transplant Proc 1995;27:3519-20.

11. Schiodt FV, Atillasoy E, Shakil AO, et al. Etiology and outcome for 295 patients with acute liver failure in the United States. the effect of thiopental results from a reduction in CBF. Furthermore, it is not known whether ICP can be reduced by other sedatives, ie, short acting benzodiazepines.

\section{Future management}

Hypothermia: Recently, mild hypothermia has been suggested as a new powerful treatment modality to reduce ICP in ALF (47). Mild hypothermia $\left(33^{\circ} \mathrm{C}\right)$ reduces $\mathrm{CBF}$ and cerebral blood volume. It probably also restores the normal balance between the Starling forces, preventing edema. Although the rapid and dramatic effect of mild hypothermia on ICP seems promising, it awaits further study in controlled clinical trials (63).

Cyclo-oxygenase inhibition: In patients with ALF and severe $\mathrm{IH}$, the injection of indomethacin decreases the ICP within a few minutes by reducing cerebral blood volume (64). Indomethacin is a very potent vasoconstrictor, inhibiting cyclo-oxygenase activity. Further experimental and clinical trials are needed to establish its indications and side effects.

Ornithine-aspartate: Specific pharmacological treatments, such as ornithine-L-aspartate, may prove useful in increasing the conversion of ammonia to glutamine in muscle, preventing cerebral edema development. A preliminary study has recently reported that ornithine-aspartate prevented brain edema formation in an anhepatic experimental model of ALF (65).

\section{CONCLUSIONS}

Treatment of neurological problems in ALF has mainly been symptomatic. Recent discoveries of distinct pathophysiological mechanisms responsible for cardiovascular instability, especially IH, may allow for the evaluation of specific treatments to prevent devastating complications of liver failure within the near future.

Liver Transpl Surg 1999;5:29-34.

12. Williams R. Classification, etiology, and considerations of outcome in acute liver failure. Semin Liver Dis 1996;16:343-8.

13. Kowalski HJ, Abelman WH. The cardiac output at rest in Laennec's cirrhosis. J Clin Invest 1953;32:1025.

14. Trewby PN, Williams R. Pathophysiology of hypotension in patients with fulminant hepatic failure. Gut 1977;18:1021-6.

15. Trewby PN, Hanid MA, Mackenzie RL, Mellon PJ, Williams R. Effects of cerebral oedema and arterial hypotension on cerebral blood flow in an animal model of hepatic failure. Gut 1978;19:999-1005.

16. Bihari D, Gimson AE, Lindridge J, Williams R. Lactic acidosis in fulminant hepatic failure. Some aspects of pathogenesis and prognosis. J Hepatol 1985;1:405-16.

17. Bihari DJ, Gimson AE, Williams R. Cardiovascular, pulmonary and renal complications of fulminant hepatic failure. Semin Liver Dis 1986;6:119-28.

18. de la Mata M, Meager A, Rolando N, et al. Tumor necrosis factor production in fulminant hepatic failure: relation to aetiology and superimposed microbial infection. Clin Exp Immunol 1990;82:479-84.

19. Wilkinson SP, Arroyo V, Gazzard BG, Moodie H, Williams R. Relation of renal impairment and haemorrhagic diethesis to endotoxaemia in fulminant hepatic failure. Lancet 1974;i:521-4.

20. Harrison P, Wendon J, Williams R. Evidence of increased guanylate cyclase activation by acetylcysteine in fulminant hepatic failure. Hepatology 1996;23:1067-72.

21. Schneider F, Lutun P, Boudjema K, Wolf P, Tempe JD. In vivo evidence of enhanced guanylyl cyclase activation during the hyperdynamic circulation of acute liver failure. Hepatology 1994;19:38-44. 
22. Ellis A, Wendon J. Circulatory, respiratory, cerebral, and renal derangements in acute liver failure: pathophysiology and management. Semin Liver Dis 1996;16:379-88.

23. O'Grady JG, Alexander GJ, Hayllar KM, Williams R. Early indicators of prognosis in fulminant hepatic failure. Gastroenterology 1989;97:439-45.

24. Harrison PM, Wendon JA, Gimson AE, Alexander GJ, Williams R. Improvement by acetylcysteine of hemodynamics and oxygen transport in fulminant hepatic failure. N Engl J Med 1991;324:1852-7.

25. Walsh TS, Hopton P, Lee A. A comparison between the Fick method and indirect calorimetry for determining oxygen consumption in patients with fulminant hepatic failure. Crit Care Med 1998;26:1200-7.

26. Clemmesen JO, Gerbes A, Gulberg V, et al. Hepatic blood flow and splanchnic oxygen consumption in patients with liver failure. Effects of high-volume plasmapheresis. Hepatology 1999;29:347-55.

27. Larsen FS, Ejlersen E, Clemmesen JO, Kirkegaard P, Hansen BA. Preserved cerebral oxidative metabolism in fulminant hepatic failure: an autoregulation study. Liver Transpl Surg 1996;2:348-53.

28. Ede RJ, Williams RW. Hepatic encephalopathy and cerebral edema. Semin Liver Dis 1986;6:107-18.

29. Cordoba J, Blei AT. Brain edema and hepatic encephalopathy. Semin Liver Dis 1996;16:271-81.

30. Clemmesen JO, Larsen FS, Kondrup J, Hansen BA, Ott P. Cerebral herniation in patients with acute liver failure is correlated with arterial ammonia concentration. Hepatology 1999;29:648-53.

31. Norenberg MD. Astrocytic-ammonia interactions in hepatic encephalopathy. Semin Liver Dis 1996;16:245-53.

32. Blei AT, Olafsson S, Therrien G, Butterworth RF. Ammonia-induced brain edema and intracranial hypertension in rats after portacaval anastomosis. Hepatology 1994;19:1431-44.

33. Cordoba J, Gottstein J, Blei AT. Glutamine, myo-Inositol, and organic brain osmolytes after portocaval anastomosis in the rat: implications for ammonia-induced brain edema. Hepatology 1996;24:919-23.

34. Roy CS, Sherrington MB. On the regulation of the blood supply of the brain. J Physiol 1890;11:85-8.

35. Reivich M. Blood flow metabolism couple in brain. In: Plum F, ed. Brain Dysfunction in Metabolic Disorders. New York: Raven Press, 1974:125-39.

36. Larsen FS. Cerebral circulation in liver failure: Ohm's law in force. Semin Liver Dis 1996;16:281-92.

37. Larsen FS, Ejlersen E, Hansen BA, Knudsen GM, Tygstrup N, Secher NH. Functional loss of cerebral blood flow autoregulation in patients with fulminant hepatic failure. J Hepatol 1995;23:212-7.

38. Paulson OB, Strandgaard S, Edvinsson L. Cerebral autoregulation. Cerebrovasc Brain Metab Rev 1990;2:161-92.

39. Strauss G, Hansen BA, Kirkegaard P, Rasmussen A, Hjortrup A, Larsen FS. Liver function, cerebral blood flow autoregulation and hepatic encephalopathy in fulminant hepatic failure. Hepatology 1997;25:837-9.

40. Wendon JA, Harrison PM, Keays R, Williams R. Cerebral blood flow and metabolism in fulminant liver failure. Hepatology 1994;19:1407-13.

41. Munoz SJ, Moritz MJ, Bell R, Northrup B, Martin P, Radomski J. Factors associated with severe intracranial hypertension in candidates for emergency liver transplantation. Transplantation 1993;55:1071-4.

42. Durham S, Yonas H, Aggarwal S, Darby J, Kramer D. Regional cerebral blood flow and $\mathrm{CO}_{2}$ reactivity in fulminant hepatic failure. J Cereb Blood Flow Metab 1995;15:329-35.

43. Strauss G, Hansen BA, Knudsen GM, Larsen FS. Hyperventilation restores cerebral blood flow autoregulation in patients with acute liver failure. J Hepatol 1998;28:199-203.

44. Ringe B, Lubbe N, Kuse E, Frei U, Pichlmayr R. Total hepatectomy and liver transplantation as a two-stage procedure. Ann Surg 1993;218:3-9.

45. Rozga J, Podesta L, LePage E, et al. Control of cerebral oedema by total hepatectomy and extracorporeal liver support in fulminant hepatic failure. Lancet 1993;342:898-9.

46. Ejlersen E, Larsen FS, Pott F, Gyrtrup HJ, Kirkegaard P, Secher NH. Hepatectomy corrects cerebral hyperperfusion in fulminant hepatic failure. Transplant Proc 1994;26:1794-5.

47. Cordoba J, Crespin J, Gottstein J, Blei AT. Mild hypothermia modifies ammonia-induced brain edema in rats after portacaval anastomosis. Gastroenterology 1999;116:686-93

48. Bernuau J, Rueff B, Benhamou JP. Fulminant and subfulminant liver failure: definitions and causes. Semin Liver Dis 1986;6:97-106.

49. Larsen FS, Ejlersen E, Hansen BA, Mogensen T, Tygstrup N, Secher NH. Systemic vascular resistance during high-volume plasmapheresis in patients with fulminant hepatic failure: relationship with oxygen consumption. Eur J Gastroenterol Hepatol
1995; 7:887-92

50. Hughes RD, Pucknell A, Routley D, Langley PG, Wendon JA, Williams R. Evaluation of the BioLogic-DT sorbent-suspension dialyser in patients with fulminant hepatic failure. Int J Artif Organs 1994;17:657-62

51. Lidofsky SD, Bass NM, Prager MC, et al. Intracranial pressure monitoring and liver transplantation for fulminant hepatic liver failure. Hepatology 1992;16:1-7.

52. Blei AT, Olafsson S, Webster S, Levy R. Complications of intracranial pressure monitoring in fulminant hepatic failure. Lancet 1993;341:157-8.

53. Larsen FS, Ranek L, Hansen BA. Pitfalls in intracranial pressure monitoring in fulminant hepatic failure. J Hepatol 1997;26:451-2.

54. Larsen FS, Pott F, Hansen BA, et al. Transcranial Doppler sonography may predict brain death in patients with fulminant hepatic failure. Transplant Proc 1995;27:3510-1.

55. Davies MH, Mutimer D, Lowes J, Elias E, Neuberger J. Recovery despite impaired cerebral perfusion in fulminant hepatic failure. Lancet 1994;343:1329-30

56. Larsen FS, Knudsen GM, Hansen BA. Pathophysiological changes in cerebral circulation, oxidative metabolism and blood-brain barrier in patients with acute liver failure. Tailored cerebral oxygen utilization. J Hepatol 1997;27:231-8.

57. Larsen FS, Olsen KS, Ejlersen E, Hansen BA, Paulson OB, Knudsen GM. Cerebral blood flow autoregulation and transcranial Doppler sonography in patients with cirrhosis. Hepatology 1995;22:730-6.

58. Aggarwal S, Kramer D, Yonas H, et al. Cerebral hemodynamic and metabolic changes in fulminant hepatic failure: a retrospective study. Hepatology 1994;19:80-7.

59. Larsen FS, Hansen BA, Ejlersen E, et al. Cerebral blood flow, oxygen metabolism and transcranial Doppler sonography during high-volume plasmapheresis in fulminant hepatic failure. Eur J Gastroenterol Hepatol 1996;8:261-5.

60. Canalese J, Gimson AE, Davis C, Mellon PJ, Davis M, Williams R. Controlled trial of dexamethasone and mannitol for the cerebral oedema of fulminant hepatic failure. Gut 1982;23:625-9.

61. Ede RJ, Gimson AE, Bihari D, Williams R. Controlled hyperventilation in the prevention of cerebral oedema in fulminant hepatic failure. J Hepatol 1986;2:43-51.

62. Forbes A, Alexander GJ, O'Grady JG, et al. Thiopental infusion in the treatment of intracranial hypertension complicating fulminant hepatic failure. Hepatology 1989;10:306-10.

63. Jalan R, Damink SW, Deutz NE, Lee A, Hayes PC. Moderate hypothermia for uncontrolled intracranial hypertension in acute liver failure. Lancet 1999;354:1164-8.

64. Clemmesen JO, Hansen BA, Larsen FS. Indomethacin normalizes intracranial pressure in acute liver failure: a twenty-three-year-old woman treated with indomethacin. Hepatology 1997;26:1423-5.

65. Rose C, Michalak A, Rao KV, Quack G, Kircheis G, Butterworth RF. L-ornithine-L-aspartate lowers plasma and cerebrospinal fluid ammonia and prevents brain edema in rats with acute liver failure. Hepatology 1999;30:636-40.

66. Bernuau J, Goudeau A, Poynard T. Multivariate analysis of prognostic factors in fulminant hepatitis B. Hepatology 1986;6:648-51.

67. Pauwels A, Mostefa-Kara N, Florent C, Levy VG. Emergency liver transplantation for acute liver failure. Evaluation of London and Clichy criteria. J Hepatol 1993;17:124-7.

68. Ranek L, Andreasen PB, Tygstrup N. Galactose elimination capacity as a prognostic index in patients with fulminant liver failure. Gut 1976;17:959-64

69. Saibara T, Onishi S, Sone J, et al. Arterial ketone body ratio as a possible indicator for liver transplantation in fulminant hepatic failure. Transplantation 1991;51:782-6.

70. Takahashi Y, Kumada H, Shimizu M, et al. A multicenter study on the prognosis of fulminant viral hepatitis: early prediction for liver transplantation. Hepatology 1994;19:1065-71.

71. Van Thiel DH. When should a decision to proceed with transplantation actually be made in cases of fulminant or subfulminant hepatic failure: at admission to hospital or when a donor organ is made available? J Hepatol 1993;17:1-2.

72. Donaldson BW, Gopinath R, Wanless IR, et al. The role of transjugular liver biopsy in fulminant liver failure: relation to other prognostic indicators. Hepatology 1993;18:1370-6.

73. Lee WM, Galbraith RM, Watt GH, et al. Predicting survival in fulminant hepatic failure using serum Gc protein concentrations. Hepatology 1995;21:101-5. 


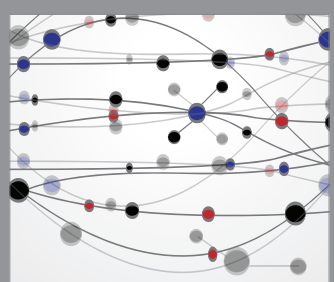

The Scientific World Journal
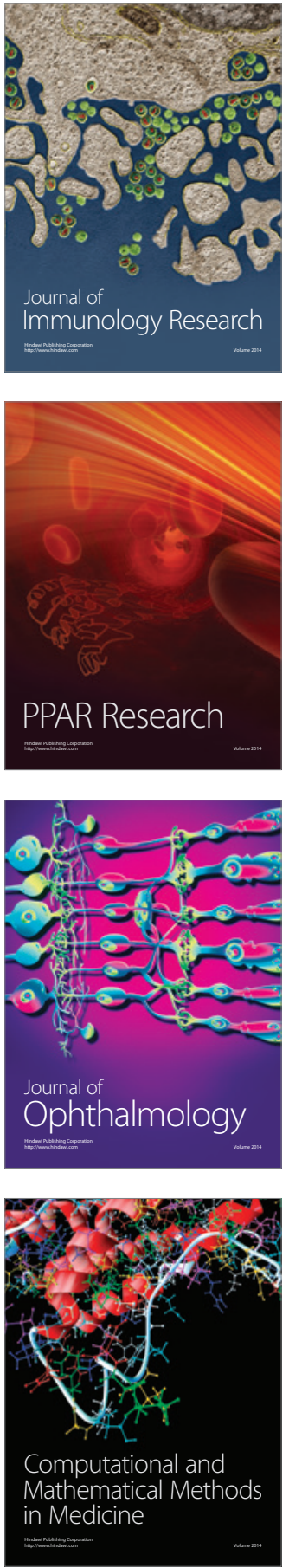

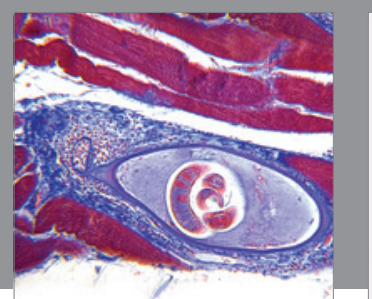

Gastroenterology Research and Practice

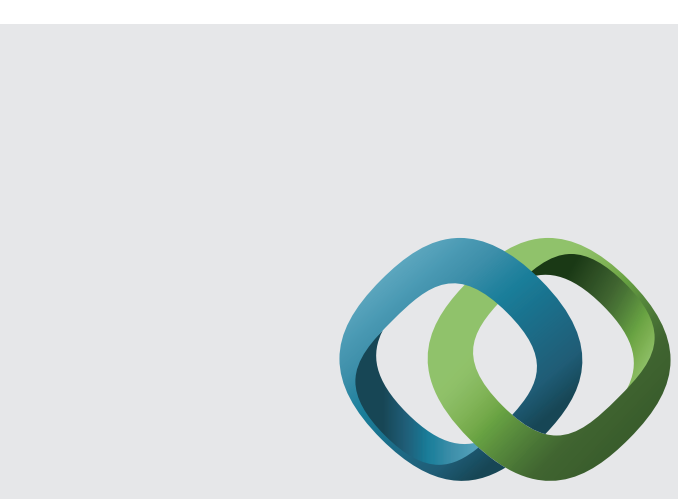

\section{Hindawi}

Submit your manuscripts at

http://www.hindawi.com
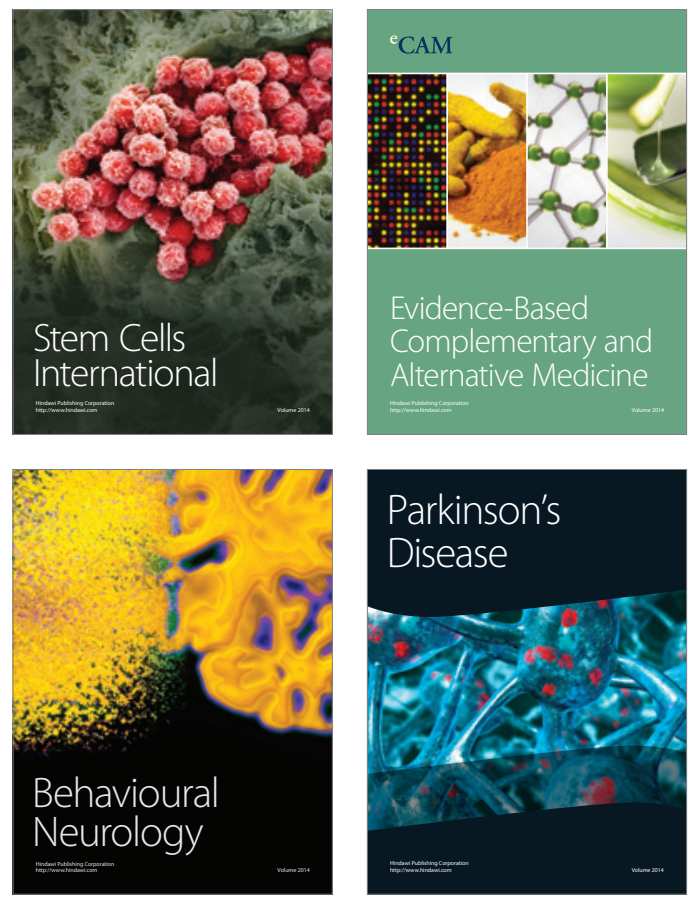
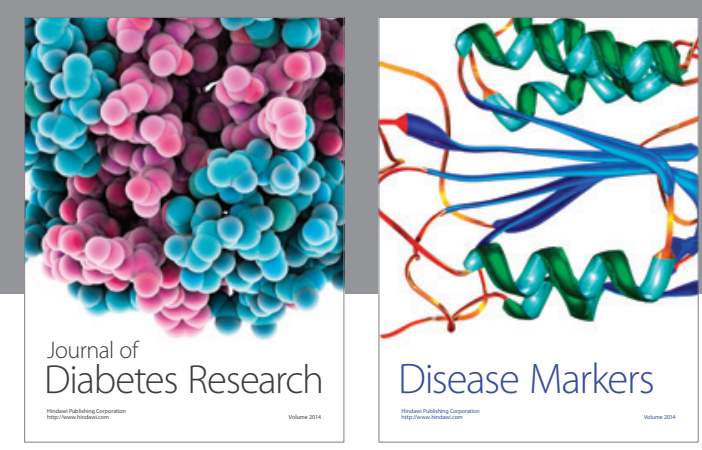

Disease Markers
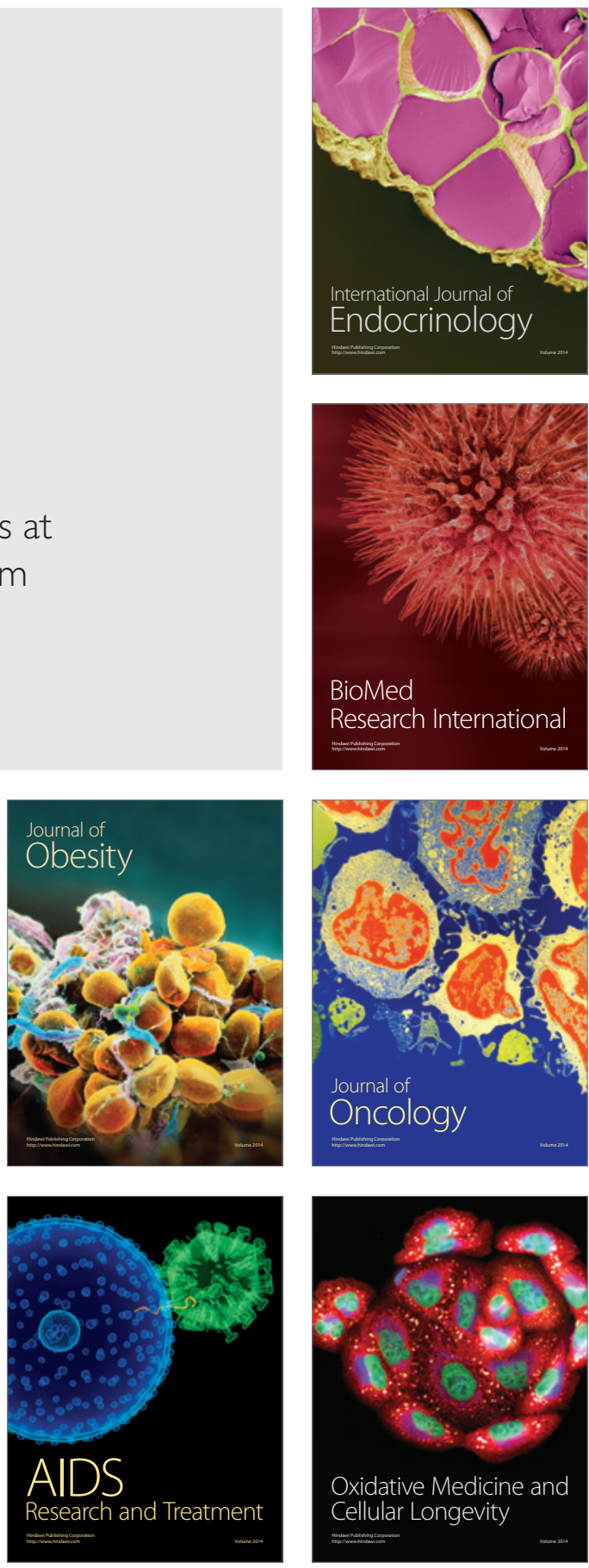